\title{
TRP channels as sensors of oxygen availability.
}

$\operatorname{AUTHOR}(S):$

Numata, Tomohiro; Ogawa, Nozomi; Takahashi, Nobuaki; Mori, Yasuo

\section{CITATION:}

Numata, Tomohiro ...[et al]. TRP channels as sensors of oxygen availability.. Pflügers Archiv : European journal of physiology 2013, 465(8): 1075-1085

\section{ISSUE DATE:}

2013-08

URL:

http://hdl.handle.net/2433/189741

\section{RIGHT:}

The final publication is available at Springer via http://dx.doi.org/10.1007/s00424-0131237-9; This is not the published version. Please cite only the published version.; この論文 は出版社版でありません。引用の際には出版社版をご確認ご利用ください。 
TRP channels as sensors of oxygen availability

Tomohiro Numata ${ }^{1,2}$, Nozomi Ogawa ${ }^{1}$, Nobuaki Takahashi ${ }^{1,3}$ and Yasuo Mori ${ }^{1,2,4^{*}}$

${ }^{1}$ Laboratory of Molecular Biology, Department of Synthetic Chemistry and Biological Chemistry, Graduate School of Engineering, Kyoto University, Kyoto, Japan

${ }^{2}$ Laboratory of Environmental Systems Biology, Department of Technology and Ecology, Hall of Global Environmental Studies, Kyoto University, Kyoto, Japan

${ }^{3}$ Advanced Biomedical Engineering Research Unit, Kyoto University, Kyoto, Japan ${ }^{4}$ CREST, Japan Science and Technology Agency, Chiyoda-ku, Tokyo, Japan

${ }^{*}$ Correspondence:

Laboratory of Molecular Biology, Department of Synthetic Chemistry and Biological Chemistry, Graduate School of Engineering, and Laboratory of Environmental Systems Biology, Department of Technology and Ecology, Hall of Global Environmental Studies, Kyoto University, Kyoto 615-8510, Japan

E-mail: mori@sbchem.kyoto-u.ac.jp

Tel: +81-75-383-2761

Fax: +81-75-383-2765 


\section{Abstract}

An ability to adapt to changes in oxygen availability is essential for survival in both prokaryotic and eukaryotic organisms. Recently, cation channels encoded by the transient receptor potential (trp) gene superfamily have been recognized as multimodal sensors of a wide variety of factors inside the cells and in the extracellular environment, and also as transducers of electrical and chemical signals mediated by ions such as $\mathrm{Ca}^{2+}$. The functional features of TRP channels enable the body to react and adapt to different forms of environmental changes, including oxygen levels. A sub-class of TRP channels regulate various cellular processes in response to fluctuations in oxygen. In this article, we describe the physiological and pathological significance of the oxygen-sensitive TRP channels, which are heterogeneous in the cellular responses to acute changes in oxygen, by contrasting their oxygen-monitoring function with that of other ion channels, transporters and enzymes. We also discuss physiological relevance of oxygen-sensitive TRP channels as a novel class of target proteins for pharmaceutical therapeutics.

Keywords: TRP channels; oxygen; cysteine; TRPA1; $\mathrm{Ca}^{2+}$ 


\section{Introduction}

Living organisms, from bacteria to humans, possess mechanisms for oxygen $\left(\mathrm{O}_{2}\right)$ homeostasis. Cellular $\mathrm{O}_{2}$ concentrations must be tightly regulated within a narrow physiological range for organisms to flourish. In aerobic organisms, both $\mathrm{O}_{2}$ deprivation and excess can be deleterious: hypoxia stifles ATP generation and results in breakdown of essential cellular functions, whereas hyperoxia drives the generation of reactive oxygen intermediates that can cause lethal damage to membranes and DNA.

There are a variety of tissues that sense the $\mathrm{O}_{2}$ level, including Type I cells of the carotid body, neuroepithelial bodies in the lungs, chromaffin cells in the fetal adrenal medulla and smooth muscle cells in the pulmonary, fetoplacental and systemic arteries and the ductus arteriosus. The $\mathrm{O}_{2}$ sensitivity of these tissues varies depending on their anatomical location, and together they constitute a homeostatic $\mathrm{O}_{2}$-sensing system $(73,113)$.

Cellular responses to changes in $\mathrm{O}_{2}$ availability can be acute or chronic (60). Acute responses rely mainly on $\mathrm{O}_{2}$-regulated ion channels, which mediate adaptive changes in cell excitability, contractility and secretory activity (32, 52, 60, 73, 112). Ion channels are well suited for detecting acute and rapid changes in the environment owing to their fast kinetics and plasma membrane localization, as a direct interface with the extracellular environment. There are two major ways in which ion channels sense $\mathrm{O}_{2}$ : firstly through direct alternation of the redox status of channel proteins themselves via modification of thiol-rich molecules (direct pathways) and secondly through interaction with complexes with other proteins carrying $\mathrm{O}_{2}$ sensor domains (indirect pathway). Most of the channels sense $\mathrm{O}_{2}$ through the indirect pathways. Ryanodine-sensitive $\mathrm{Ca}^{2+}$ release channel (ryanodine receptor; RyR) and TRPA1 channel are the representative 
ion channels that take the direct pathway $(57,102)$. On the other hand, chronic responses depend on the modulation of transcription factors such as hypoxia-inducible factor (HIF), which determines the expression of numerous genes encoding growth factors, enzymes and transporters $(92,93,111)$.

Drosophila melanogaster transient receptor potential (trp) protein and its homologs are putative six-transmembrane polypeptide subunits that assemble into tetramers to form channels. In mammalian systems, TRP channels comprise six related protein subfamilies: TRPC, TRPV, TRPM, TRPA, TRPP and TRPML (29). These channels are activated by sensing diverse stimuli, including receptor stimulation, heat, osmotic pressure and mechanical and oxidative stress from the extracellular and intracellular milieu (29, 78, 109). Recently, a class of TRP channels was found to be modulated by hypoxia and hyperoxia and to control various cellular processes in response. This review explores the physiological and pathological significance of the $\mathrm{O}_{2}$-sensitive TRP channels (Fig. 1), and compare their $\mathrm{O}_{2}$-monitoring function with that of other ion channels, transporters and enzymes to demonstrate the heterogeneity in cellular responses specifically to acute changes in $\mathrm{O}_{2}$. Their responses to chronic changes in $\mathrm{O}_{2}$ have been excellently reviewed elsewhere (30, 35, 53, 89, 90, 92, 94, 112, 115) and will not be covered in detail here. 


\section{Distinctive sensing function of TRP channels}

The TRPC homologs are receptor-activated $\mathrm{Ca}^{2+}$-permeable cation channels (RACCs) that are activated by sensing metabotoropic changes upon receptor stimulation, which activates and induce phospholipase $\mathrm{C}$ (PLC) to hydrolyze phosphatidylinositol-4,5-bisphosphate into inositol-1,4,5-trisphosphate $\left(\mathrm{IP}_{3}\right)$ and diacylglycerol (DAG) $(77,106)$. TRPV $\mathrm{Ca}^{2+}$-permeable channels can be functionally defined as thermosensors $(10,29,55,106,109)$, but they are in fact sensors for diverse stimuli. TRPV5 and TRPV6 are distinct from other TRPVs because they are the only highly $\mathrm{Ca}^{2+}$-selective channels and tightly regulated by intracellular $\mathrm{Ca}^{2+}\left(\left[\mathrm{Ca}^{2+}\right]_{\mathrm{i}}\right)$ in the TRP family $(76,78)$. The TRPM subfamily is named after melastatin (TRPM1), a tumor suppressor protein isolated in a screen for genes whose level of expression was inversely correlated with the severity of metastatic potential in a melanoma cell line (21). TRPM8 channels, in contrast to TRPV, are activated by low temperatures $\left(<25^{\circ} \mathrm{C}\right)$ and menthol $(63,84)$. Regarding the temperature sensitivity, the principle of temperature-dependent gating in cold-sensitive TRPM8 and heat-sensitive TRPV1 channels have recently been shown $(107,108)$. The sole member of the TRPA subfamily, TRPA1, has a large amino-( $N-)$ terminal domain with 14-19 ankyrin repeats (AR) (28, 75), and is activated by pungent compounds (e.g. allyl isothiocyanate found in mustard oil) and noxious cold stimuli $\left(<17^{\circ} \mathrm{C}\right)(47,75,97)$. Thus, TRP channels serve as sensors for a variety of environmental factors, and the $\mathrm{Ca}^{2+}$ influx communicated via these TRP channels regulates a diverse array of cellular processes.

\section{$\mathrm{O}_{2}$-sensing by TRPA1 channels in vagal and sensory neurons}


Sensory and vagal afferent neurons, which project nerve endings throughout the body, have been reported to detect hypoxia in organs such as the airway, lungs and heart after ischemia and other conditions of low $\mathrm{O}_{2}$ supply (19, 34, 42, 59). However, hypoxia detection by sensory and vagal neurons was controversial and elusive (59). In terms of hyperoxia, Caenorhabditis elegans appears to be adept at evading hyperoxia owing to detection mechanisms in sensory neurons (33). Furthermore, insects breathe discontinuously to avoid $\mathrm{O}_{2}$ toxicity during hyperoxia (41). However, the physiological relevance of hyperoxia detection through sensory/autonomic systems is less clear in vertebrates, and the delineation of these vertebrate neuronal hyperoxia-sensing molecular processes remains an exciting area of research.

In mammals, enhanced discharges in vagal afferents induce respiratory, cardiac and vascular responses $(50,59,65)$ and chemicals encountered in the airway are detected by airway vagal C fibers (50). Recently, TRPA1 has been shown to sense environmental irritants, thus initiating defensive reflexes such as coughing and respiratory depression in the $C$ fibers $(10,11,72)$. Notably, our group has shown that TRPA1 in vagal and sensory neurons detects changes in $\mathrm{O}_{2}$ levels (102) and has a reverse bell-shaped $\mathrm{O}_{2}$ dependency with minimum activity at a partial $\mathrm{O}_{2}$ pressure $\left(\mathrm{PO}_{2}\right)$ of $137 \mathrm{mmHg}$, slightly below the atmospheric $\mathrm{PO}_{2}$ of $159 \mathrm{mmHg}$ (106) (Fig. 2). Corroborating this finding is the observation that disruption of the Trpa1 gene in mice abolishes hyperoxia- and mild hypoxia $\left(15 \% \mathrm{O}_{2}\right)$-induced cationic currents in vagal and sensory neurons and thereby impedes enhancement of in vivo vagal discharges induced by hypoxia (102). These results suggest that TRPA1 has a previously unidentified role as an $\mathrm{O}_{2}$ sensor. 


\section{Molecular mechanisms underlying $\mathrm{O}_{2}$-sensing by TRPA1}

TRPA1 is characterized by a large $N$-terminal domain with 17 predicted AR (28), and have a tetrameric assembly with a compact transmembrane domain and a basket-like cytoplasmic domain structure (18). TRPA1 is activated by a variety of electrophilic compounds, including endogenous inflammatory mediators, products of oxidative stress and exogenous pungent chemicals. These compounds are potentially susceptible to nucleophilic attack by the sulfhydryl groups of cysteine (Cys) residues (7, $62)$.

Sensing of hypoxia by TRPA1 is based on proline (Pro) hydroxylation by Pro hydroxylases (PHDs). In normoxia, PHDs hydroxylate the conserved Pro394 residue in the 10th AR of human TRPA1, inhibiting its activity. Hypoxia impairs PHD activity, relieving TRPA1 from the inhibitory action of Pro hydroxylation and leading to an increase in its activity, achieved either by insertion of fresh, unmodified TRPA1 proteins into the plasma membrane or by dehydroxylation of modified proteins through an unidentified molecular mechanism (102).

Sensing of hyperoxia by TRPA1 is mediated by Cys modification. In order to evaluate the oxidation sensitivity of TRP channels quantitatively, we systematically compared the responses of redox-sensitive TRP channels (TRPA1, TRPV1, TRPV2, TRPV3, TRPV4 and TRPC5) with a congeneric series of reactive disulfides, which show differential electron acceptor (oxidation) abilities indicated as redox potentials obtained using rotating disc-electrode voltammetry (102, 117). Strikingly, among the TRPs tested, only TRPA1 responded to inert electrophiles with a redox potential of $-2,950 \mathrm{mV}$. The redox potential of $\mathrm{O}_{2}(-2,765 \mathrm{mV})$ is less negative than the threshold redox potential for TRPA1 (approximately $-3,400 \mathrm{mV}$ ) but is more negative than that 
for the other channels investigated (Fig. 3), suggesting that TRPA1 is activated by $\mathrm{O}_{2}$ (a weak oxidant) to function as a hyperoxia sensor (102). In this paradigm, $\mathrm{O}_{2}$ activates TPRA1 by oxidizing Cys633 and/or Cys856, located within the 17th AR and the intracellular linker region between S4 and S5, respectively. TRPA1 can assume at least two oxidized forms during hyperoxia: a relatively unstable oxidized state (State 1) readily reversed by glutathione, and a relatively stable oxidized state (State 2). It is conceivable that sulfhydryl groups on the key Cys residues (Cys633 and Cys856) are modified to sulfenic acid (S-OH) in State 1, and form disulfide bonds (S-S) in State 2 (102). This oxidation mechanism activates TRPA1 by overriding the inhibition exerted by Pro hydroxylation. To illustrate this phenomenon, single-channel currents were significantly enhanced by hyperoxic solution but not by hypoxic solution applied from the intracellular side of cell-free excised inside-out patches. These results imply that TRPA1 is activated by a direct action of $\mathrm{O}_{2}$ in hyperoxia, and by intracellular $\mathrm{O}_{2}$-sensing mediators in hypoxia (102). In physiological conditions, glutathione and thioredoxin systems can regulate the redox balance for TRPA1 activation.

Regulation via Cys oxidation by oxidants, reductants and electrophiles is not unique to TRPA1 among ion channels. A form of $\mathrm{O}_{2}$ sensing has also been proposed involving the effects of $\mathrm{PO}_{2}$ on the number of Cys residues present in the RyR. In skeletal muscle cells, RyR is localized on the sarcoplasmic reticulum (SR) and interacts directly with voltage-gated $\mathrm{Ca}^{2+}$ channels to initiate muscle contraction. RyR has 100 Cys residues per subunit, $\approx 20$ of which are free for redox modifications $(4,99,110)$. A number of redox-sensitive Cys residues have been identified in both the open and closed states of the channel and appear to be distributed across the primary structure of the cytoplasmic region $(4,110)$. Several of these sites, including Cys36 and Cys315, have 
been mapped to the clamp domains $(3,36,57,58)$ involved in inducing a major conformational changes to open and close the channel (54), whereas Cys3635 is located in subdomain 3 of the calmodulin binding site in rabbit RyR (99). The S-nitrosylation of Cys3635 appears to occur only at physiological tissue $\mathrm{O}_{2}$ tension $\left(\mathrm{PO}_{2} \approx 10 \mathrm{~mm} \mathrm{Hg}\right)$ and facilitates muscle contraction (23). Recently, a combination of fluorescence detection and mass spectrometry of RyR1 identified two redox-sensitive Cys residues (Cys1040 and Cys1303) that were labeled in the presence of reduced and oxidized glutathione (87). A $\left[{ }^{3} \mathrm{H}\right]$-based ryanodine ligand binding assay also revealed that point substitution of each of 18 Cys residues with serine (Ser) or alanine modulated the RyR activity of each mutant in response to reduced and oxidized glutathione. Three single-site RyR1 mutants (Cys1781Ser, Cys2436Ser and Cys2606Ser) exhibited a reduced redox response compared with wildtype RyR1 (87), suggesting that multiple Cys residues contribute to the redox state and activity of RyR1. These Cys modifications occur via coupling of RyR1 to nicotinamide adenine dinucleotide phosphate oxidase (NOX) 4. In skeletal muscle, an increase in local $\mathrm{O}_{2}$ tension proportionally increases reactive oxygen species (ROS) produced by NOX4 located on the SR (101). This local increase in ROS at the SR causes oxidation of multiple Cys residues on RyR1 and leads to its activation (101).

\section{Anoxia-sensing mediated by TRPM7 and TRPM2 channels in the brain}

Acute neuronal damage after injury involves a complex combination of processes including excitotoxicity, inflammation, necrosis and apoptosis in the brain. The theory that activation of $N$-methyl-D-aspartate (NMDA) excitatory glutamate receptors mediates excessive $\mathrm{Ca}^{2+}$ entry and precipitates critical excitotoxic events that result in 
neuronal death has been enthusiastically embraced given the prospect of using NMDA receptor antagonists to prevent the associated brain injury. Unfortunately, these receptor antagonists fail to act effectively as an anti-excitotoxicity therapy (AET) for human stroke $(12,43)$. In addressing this problem, Aarts et al. have revealed that the TRPM7 channel, termed 'chanzyme', a channel equipped with an $\alpha$-kinase domain $(70,91)$, is activated by oxygen-glucose deprivation through the production of ROS and reactive nitrogen species (RNS), facilitating $\mathrm{Ca}^{2+}$ uptake that further stimulates ROS production and TRPM7 activation in heterologous expression systems and rat cortical neurons (1). Suppressing TRPM7 expression in rat cortical neurons prevents anoxic neuronal death even in the absence of AET, indicating that TRPM7 is an essential mediator of anoxic death. It is possible that patients enrolled in failed trials studying the use of AET for stroke or traumatic brain injury were selected to have severe injuries $(5,67)$ or that these disorders in humans, by their nature, induce severe ischemia. TRPM7 may be activated in these rigorous ischemic conditions. Therefore, future treatment of such disorders may also need to inhibit TRPM7. Indeed, it has been shown that suppression of hippocampal TRPM7 by intrahippocampal injections of viral vectors bearing short hairpin RNA specific for TRPM7 makes neurons resistant to ischemic death after brain ischemia and preserves neuronal morphology and function in rats (98). TRPM7 suppression also prevents ischemia-induced deficits in long-term potentiation and preserves performance in fear-associated and spatial-navigational memory tasks (104). Thus, regional suppression of TRPM7 is feasible and well tolerated, and inhibits delayed neuronal death in vivo in an animal model.

Recently, TRPM2 has also been implicated in anoxic neuronal cell death $(64,104)$. TRPM2, which is widely distributed in the central nervous system $(49,79,116)$, can be 
activated, directly or indirectly, by several factors that are present in excess in ischemia, including $\mathrm{H}_{2} \mathrm{O}_{2}$, ROS and RNS $(39,64)$. Moreover, TRPM2 is gated by cytosolic adenosine diphosphate ribose (ADPR). Raising $\left[\mathrm{Ca}^{2+}\right]_{\mathrm{i}}$ lowers the half-maximal effector concentration for channel activation by ADPR (86). In ischemia, the influx of $\mathrm{Na}^{+}$and $\mathrm{Ca}^{2+}$ through TRPM2 channels, which promotes membrane depolarization, mitochondrial membrane disruption and increase in the $\left[\mathrm{Ca}^{2+}\right]_{\mathrm{i}}$, may participate in a positive feedback loop in which cytosolic ADPR, ROS and RNS aggravate damages of neurons (104). Importantly, inhibiting TRPM2 by RNA interference reduces TRPM2-like currents in hippocampal neurons (79) and protects the cell against $\mathrm{H}_{2} \mathrm{O}_{2}$ toxicity in HEK cells (49), cultured neurons, and brain tissue (46), suggesting that TRPM7 and TRPM2 channels are potential therapeutic targets for reducing the ischemic cell damage and excitotoxicity that follow stroke.

\section{Hypoxia-sensing by TRPC6 channels in pulmonary smooth muscle cells}

Hypoxic pulmonary vasoconstriction (HPV) is an essential mechanism in the lung for matching blood perfusion to ventilation during local alveolar hypoxia and functions to optimize pulmonary gas exchange (114). Disturbances in HPV can cause life-threatening hypoxemia, whereas chronic hypoxia triggers vascular remodeling in the lungs and pulmonary hypertension $(71,114,115)$. TRPC6 appears to be a key regulator of acute HPV. In studying the signaling cascades that comprise this vitally important mechanism, Weissmann et al. illustrated that although recombinantly expressed TRPC6 cannot be activated by hypoxia, severe hypoxia ( $\left.1 \% \mathrm{O}_{2}\right)$-induced cation influx and currents in smooth muscle cells are largely absent in precapillary pulmonary arteries in Trpc6-knockout mice, whereas the pulmonary vasoconstrictor 
response to the thromboxane mimetic, U46619, is unchanged (115). Hypoxia-induced TRPC6 activation in smooth muscle cells is mediated by DAG accumulation, probably downstream of activated PLCs. Accordingly, induction of regional hypoventilation results in severe arterial hypoxemia in $\operatorname{Trpc} 6$ knockout mice, but not in wild-type mice. Notably, though, chronic hypoxia-induced pulmonary hypertension is independent of TRPC6 activity. Thus, TRPC6 plays a unique and indispensable role in acute HPV. Manipulation of TRPC6 function may thus offer a therapeutic strategy for the control of pulmonary hemodynamics and gas exchange.

\section{Hypoxia-sensing by TRPC1-STIM1-Orai1 complex in pulmonary smooth muscle} cells

Stromal interacting molecule 1 (STIM1), a 90-kDa transmembrane $\mathrm{Ca}^{2+}$-binding protein found in endoplasmic reticulum and plasma membrane, has been reported to play a pivotal role in regulation by hypoxia of store-operated $\mathrm{Ca}^{2+}$ channels (SOCC) composed of TRPCs and Orai channels (82) in pulmonary arterial smooth muscle cells (PASMCs) $(61,74)$. The response of SOCC to acute hypoxia shows a initial transient followed by a sustained rise in $\left[\mathrm{Ca}^{2+}\right]_{\mathrm{i}}$ and induces colocalizations of TRPC1-STIM1 and Orai1-STIM1 complexes in PASMCs (61). Suppressing the expression of either TRPC1, STIM1 or Orai1 with small interfering RNA (siRNA) in PASMCs significantly inhibits both hypoxia-induced transient and sustained component of capacitative $\mathrm{Ca}^{2+}$ entry (CCE), suggesting a ternary complex formed by these proteins to mediate CCE (61). One possible mechanism could be that acute hypoxia triggers the production of ROS and modifies the Cys residue on STIM1 to alter its functional and physical interaction with TRPC1 and Orai1 (40, 74). Interestingly, SOCs 
may be differentially assembled by a combination of TRPC channels, STIM1, and/or Orai proteins $(82,105)$. TRPC1, TRPC6, TRPC4, TRPC3 and TRPC5 are also expressed in PASMCs (61) and these TRPC channels may also form a complex with STIM1 and/or Orai1.

\section{Hypoxia-sensing by TRP channels in the central nervous system}

The brain is particularly sensitive to hypoxia and oxidative stress (2). This vulnerability is mainly due to the extraordinary metabolic requirements of neurons to function. Vital neuronal processes such as neurotransmission and ion homeostasis are critically dependent on a continuous supply of $\mathrm{O}_{2}$ and glucose (2). During stroke and hypoxia, cranial blood vessel occlusion starves the brain of $\mathrm{O}_{2}$ and glucose. Some TRP channels clearly function as $\mathrm{O}_{2}$-sensitive channels in the central nervous system and cardiac system. For instance, TRPV4, a $\mathrm{Ca}^{2+}$-permeable cationic channel that is gated by various stimuli such as temperature and cell swelling, is involved in ischemia-induced $\mathrm{Ca}^{2+}$ entry in reactive astrocytes and participates in the pathogenic mechanisms of astroglial reactivity following ischemia. After induction of cerebral hypoxia or ischemia by bilateral occlusion of the carotids combined with hypoxic conditions and followed by reperfusion, cell swelling and cytokines or growth factor up-regulates TRPV4 expression and activity in rat hippocampal astrocytes (14). In cardiac spinal sympathetic sensory fibers and myocytes, TRPV1 and TRPC3 act as sensors of tissue ischemia $(81,95)$. These TRP channels have other non-sensory functions including release of substance $\mathrm{P}$, neurokinin $\mathrm{A}$ and calcitonin gene-related peptide from peripheral nerve terminals in the epicardial surface of the cardiac ventricle and around the coronary blood vessels. The neuropeptides induce vasodilation and 
negative inotropic and chronotropic effects to mitigate the effects of ischemia and reperfusion injury (76). Thus, TRP channels that indirectly sense $\mathrm{O}_{2}$ also have significant therapeutic potential as targets for pharmacological therapy in ischemia reperfusion and stroke.

\section{Oxygen sensing by other ion channels and transporters}

$K^{+}$channel

The most recognizable $\mathrm{O}_{2}$-regulated ion channels are $\mathrm{K}^{+}$channels in the carotid body. $\mathrm{O}_{2}$-regulated $\mathrm{K}^{+}$channels were initially studied in Type I cells of the carotid body $(13,20,27,52,83,96)$, but similar observations were later reported in the neuroepithelial body $(80,118)$, adrenal chromaffin cells $(16,103,119)$, smooth muscle cells of the pulmonary resistance arteries (88), aortic body (45), fetoplacental arteries (38) and thoracic aorta (45). $\mathrm{O}_{2}$-sensitive $\mathrm{K}^{+}$currents can be either inhibited or potentiated by hypoxia, and this dual regulation is observed even in the same channel type expressed in different cells. For example, maxi calcium-sensitive potassium $\left(\mathrm{K}_{\mathrm{Ca}}\right)$ channels are inhibited by hypoxia in rat glomus cells and fetal ovine pulmonary vascular smooth muscle, but are potentiated in cerebral arterial myocytes (60). Developmental changes affect the type and expression level of $\mathrm{O}_{2}$-sensitive $\mathrm{K}_{V}$ and TASK-1 channels (60). Nine families of $K_{V}$ channels $\alpha$-subunits are recognized from cloning studies (Kv1-9). These channels often display differences in voltage sensitivity, current kinetics and steady-state activation and inactivation. Based on patch-clamp recordings with specific $\mathrm{K}_{\mathrm{V}}$ antibodies, studies in expression systems or the use of reverse transcription polymerase chain reaction, the potential candidate $\mathrm{K}_{\mathrm{V}}$ channel $\alpha$-subunits that could form $\mathrm{O}_{2}$-sensitive channels are $\mathrm{K}_{\mathrm{V}} 1.2, \mathrm{~K}_{\mathrm{V}} 1.5, \mathrm{~K}_{\mathrm{V}} 2.1, \mathrm{~K}_{\mathrm{V}} 3.1$ and 
Kv9.3 (113). On the other hand, the members of "two-pore domain" potassium $\left(\mathrm{K}_{2 \mathrm{P}}\right)$ channels were divided into six subfamilies (TWIK, TREK, TASK, TALK, THIK and TRESK) on the basis of sequence similarity and functional resemblance (22). The $\mathrm{K}_{2 \mathrm{P}}$ channels are regulated by a wide variety of voltage-independent factors, such as $\mathrm{pH}$, temperature and membrane stretch. The pharmacological profile of $\mathrm{O}_{2}$-sensitive background $\mathrm{K}^{+}$current, together with the strong mRNA expression, suggests that TASK channels play the primary role in sensing acidosis and hypoxia in glomus cells (22). In the embryo and neonate, it seems that membrane potential is largely controlled by $\mathrm{K}_{\mathrm{Ca}}$ channels that are inhibited by hypoxia in smooth muscle cells. However, upon maturation the control of membrane potential shifts to $\mathrm{K}_{\mathrm{V}}$ and TASK-1 channels. An identical developmental shift from $\mathrm{K}_{\mathrm{Ca}}$ to $\mathrm{K}_{\mathrm{V}}$ and TASK-like channels is seen in Type I cells of the carotid body. The $\mathrm{O}_{2}$ content of fetal blood is much higher than that of adult blood (68), and it seems likely that $\mathrm{K}_{\mathrm{Ca}}$ channels contribute to the control of membrane potential at higher levels of $\mathrm{O}_{2}$, whereas $\mathrm{K}_{\mathrm{V}}$ and TASK channels act at lower $\mathrm{O}_{2}$ levels.

\section{Voltage-dependent $\mathrm{Na}^{+}$channel}

Voltage-dependent $\mathrm{Na}^{+}$channels play a key role in excitotoxic damage in ischemia. Blockers of $\mathrm{Na}^{+}$channels inhibit depolarization, thereby reducing $\mathrm{Ca}^{2+}$ influx through voltage-dependent $\mathrm{Ca}^{2+}$ and NMDA receptor channels and prevent the reversal of the $\mathrm{Ca}^{2+} / \mathrm{Na}^{+}$exchanger (15). These improve the ionic homeostasis and cellular energy levels, and prevent ischemia-hypoxia induced neuronal injury and neuronal damage mediated by $\mathrm{Ca}^{2+}$ overload. Anoxia and metabolic inhibition produce a large negative shift in the steady-state inactivation curve for the voltage-dependent $\mathrm{Na}^{+}$ current, that results in reduced $\mathrm{Na}^{+}$current amplitude in human neocortical pyramidal 
neurons and promotes neuronal survival during periods of $\mathrm{O}_{2}$ deprivation (17). However, after several minutes of hypoxia, a persistently elevated, non-inactivating $\mathrm{Na}^{+}$current was observed as the primary cause of an increase in $\left[\mathrm{Ca}^{2+}\right]_{\mathrm{i}}(37)$. These mechanisms may contribute both directly and indirectly to the sequence of events, including elevated $\left[\mathrm{Ca}^{2+}\right] \mathrm{i}$, that follow hypoxia and culminate in cell death.

\section{Voltage-dependent $\mathrm{Ca}^{+}$channels}

Increased $\left[\mathrm{Ca}^{2+}\right]_{\mathrm{i}}$ is necessary to elicit hypoxic constriction of the pulmonary resistance arteries. In PASMCs, $\left[\mathrm{Ca}^{2+}\right]_{\mathrm{i}}$ is increased by $\mathrm{Ca}^{2+}$ influx through $\mathrm{Ca}^{2+}$-permeable channels, such as TRPC6 channel (see above), and/or by $\mathrm{Ca}^{2+}$ mobilization from intracellular $\mathrm{Ca}^{2+}$ stores. Under hypoxic conditions, the influx of extracellular $\mathrm{Ca}^{2+}$ across the cell membrane is perhaps the predominant mechanism for increasing the $\left[\mathrm{Ca}^{2+}\right]_{\mathrm{i}}$ in PASMCs (115), and employs L-type voltage-dependent $\mathrm{Ca}^{2+}$ channels under the regulatory control of the resting membrane potential. In freshly dispersed rabbit arterial myocytes, hypoxia selectively and reversibly inhibits L-type $\mathrm{Ca}^{2+}$ channel activity, whereas T-type $\mathrm{Ca}^{2+}$ channel-mediated current is unaltered (25, 26). Hypoxia similarly inhibits recombinantly expressed L-type channels (24).

A single type of ion channel can often have bidirectional effects, activating a physiological function in one tissue but inhibiting the same function in another. L-type $\mathrm{Ca}^{2+}$ channels are present in both conduit (proximal) and resistance (distal) myocytes, but the density of these channels is approximately double in the resistance myocytes. Although the L-type channels are structurally and functionally homogeneous, influx of $\mathrm{Ca}^{2+}$ into the smooth muscle cells of the resistance arteries is enhanced by hypoxia, while in the conduit smooth muscle cells it is inhibited (25). In addition, in pacemaker 
neurons of the rostral ventrolateral medulla, hypoxia activates $\mathrm{Ca}^{2+}$ current (100). These variable responses of the L-type $\mathrm{Ca}^{2+}$ channel to hypoxia are probably due to spatial or quantitative differences in expression that have not yet been characterized, or to unidentified cell-specific $\mathrm{O}_{2}$-sensitive factors that modulate the L-type $\mathrm{Ca}^{2+}$ channel in these locations.

\section{Ion transporters}

Some ion transporters are also sensitive to changes in $\mathrm{O}_{2}$ level. Multiple $\mathrm{O}_{2}$-sensitive ion transporters play roles in ion homeostasis within red blood cells (RBCs) to control cellular volume and integrity (31). These transporters include the $\mathrm{Na}^{+}-\mathrm{K}^{+}$-Cl--cotransporter (NKCC), $\mathrm{K}^{+}-\mathrm{Cl}^{-}$-cotransporter (KCC) and $\mathrm{Na}^{+} / \mathrm{H}^{+}$exchanger (NHE), each of which responds differently to changes in $\mathrm{O}_{2}$.

NKCC is inhibited by hyperoxia and stimulated by hypoxia, as observed in a number of avian species (31). In turkey RBCs, hypoxia is the major physiological stimulus for NKCC activity with a $\mathrm{PO}_{2}$ for half-maximal activation of $\approx 41 \mathrm{mmHg}(69)$. Interestingly, $\mathrm{O}_{2}$ levels also regulate the effect of other stimuli on the activity of NKCC. At normal $\mathrm{O}_{2}$ levels, $\mathrm{NKCC}$ is activated by $\beta$-adrenergic stimulation and cell volume shrinkage, but hypoxia causes the transporter to become unresponsive to these stimuli (69).

The response of KCC to change in $\mathrm{O}_{2}$ depends on presence or absence of the stimuli such as urea, $\mathrm{pH}, \beta$-adrenergic agonist and cell swelling. For example, KCC is inhibited by hypoxia and potentiated by raising $\mathrm{PO}_{2}(60)$ KCC is activated by cell swelling, acidification and urea but in hypoxia, the transporter is inactivated and becomes refractory to activation by these other stimuli (31). It is possible that this 
regulatory mechanism fully activates KCC in arterial blood under hyperoxia, to prevent RBC shrinkage but inactivates KCC in kidney medulla and muscle beds under hypoxia. In some cases, hypoxia stimulates KCC, and may even be a prerequisite for transporter function $(9,31)$. In other cases, $\mathrm{O}_{2}$ has no effect. In several teleosts (e.g. trout, sea bream) and in frog RBCs, hypoxia increases the response to $\beta$-adrenergic agonists in lamprey RBCs and intracellular acidification. However, in these species, hypoxia is not a prerequisite for transporter function, but rather amplifies the response to the agonist (9, 31).

Like NKCC, NHE activity in RBCs is often increased by hypoxia $(48,66)$. The NHE is controlled by multiple stimuli including cell shrinkage, intracellular acidification and $\beta$-adrenergic stimulation, interacting with a number of different stimuli, some of which are $\mathrm{O}_{2}$-sensitive, others that are $\mathrm{O}_{2}$-independent. The diversity of mechanisms by which $\mathrm{O}_{2}$ modulates NHE may reflect the multiple roles of NHE in different species and transduction pathways.

\section{Glucose transporters}

The initial step in the metabolism of glucose is its transport across the plasma membrane, a step that is "rate-limiting" in the vast majority of cells and tissues. In hypoxia, glucose transport is important in tissues such as skeletal and cardiac muscle and brain that have immediate energy demands. Hypoxia mediates the enhancement of glucose transport by firstly inducing the translocation of GLUT-1 and GLUT-4 glucose transporters from intracellular vesicles to the plasma membrane, and secondly by activating preexisting GLUT-1 in the membrane (8). 


\section{$\mathrm{O}_{2}$-sensitive factors coupled to ion channels}

\section{NADPH oxidases}

NOX contain heme, flavin adenine dinucleotide, and transmembrane domains, and transfer electrons from nicotinamide adenine dinucleotide phosphate (NADPH) to $\mathrm{O}_{2}$ to generate superoxide anion $\left(\mathrm{O}_{2}^{-}\right)$that participates in intracellular signaling (6). In hypoxia, human PASMC produce transforming growth factor- $\beta 1$ (TGF- $\beta 1$ ) that induces the expression of insulin-like growth factor binding protein-3 (IGFBP-3) via the PI3K/Akt pathway. This IGFBP-3 increases NOX4 gene expression, resulting in cell proliferation (44). In hyperoxia, NOX4 mRNA and protein expression are upregulated and are involved in ROS production in human pulmonary artery endothelial cells. In addition, hyperoxia-induced cell migration and capillary tube formation are regulated by ROS generated via a NOX4-dependent pathway (85). Thus, NOX4 can be an $\mathrm{O}_{2}$ sensor. As mentioned above, ROS are generated in proportion to $\mathrm{PO}_{2}$ by NOX4 in the SR and the consequent oxidation of a small set of RyR1 Cys-thiols results firstly in increased RyR1 activity and $\mathrm{Ca}^{2+}$ release in isolated SR and in cultured myofibers, and secondly in enhanced contractility of intact muscle (101). Another molecule proposed to be downstream of $\mathrm{O}_{2}$-dependent NOX4 activation is TASK-1. Hypoxia inhibits TASK-1 activity, a response that is abolished by NOX4 siRNA and NOX inhibitors (56). Further studies are needed to determine if NOX4 has any regulatory role in these fundamental $\mathrm{O}_{2}$-dependence cellular processes.

\section{Mitochondria}

An obvious site where $\mathrm{O}_{2}$ sensing is vital is the mitochondrion because this organelle consumes $\mathrm{O}_{2}$ in the final step of the electron transport chain. Historically, a 
model of $\mathrm{O}_{2}$ sensing based on the "mitochondrial model" has been advocated (51). The potential involvement of hypoxia-induced changes in mitochondrial function has been suggested from the results of experiments investigating the effects of pharmacological inhibitors on mitochondrial function. However, the role of ion channels in sensing $\mathrm{O}_{2}$ in mitochondria may not be straightforward. For example, $\mathrm{O}_{2}$ sensing in glomus cells involves inhibition of $\mathrm{O}_{2}$-sensitive $\mathrm{K}^{+}$channels that are modulated by $\mathrm{O}_{2}$ tensions higher than those that depress cellular metabolic function. Mitochondrial respiration is not limited by $\mathrm{O}_{2}$ supply until extracellular $\mathrm{PO}_{2}$ falls below 2-3 mmHg, whereas ion channels are regulated by $\mathrm{PO}_{2}$ values below $80 \mathrm{mmHg}$ (60). Therefore, the involvement of some components of the mitochondrial electron transport chain in cellular $\mathrm{O}_{2}$ sensing cannot be discounted but much remains to be elucidated about their identity and mode of interaction with the effector ion channels.

\section{Conclusion}

$\mathrm{O}_{2}$-sensitive ion channels are ubiquitous and widely distributed, and participate in many $\mathrm{O}_{2}$-dependent cellular functions. TRP channels can respond to multiple activation triggers and therefore serve as $\mathrm{O}_{2}$ detectors both in a direct and indirect manner, as part of a complex signaling system that maintains the $\mathrm{O}_{2}$ supply to the tissues and protects cells against damage. For example, in sensory and vagal neurons, TRPA1 translates $\mathrm{O}_{2}$ signals into electrical signals that enhance in vivo hypoxia-induced vagal discharges. Considering that TRPA1 activation exhibits an inverted bell-shaped $\mathrm{O}_{2}$-dependency curve, this bidirectional regulation of channel activity may be advantageous because it adds versatility to the biophysical mechanisms that cells use to adapt or respond to environmental triggers. 
Despite recent advances in the molecular characterization of $\mathrm{O}_{2}$-regulated ion channels and enzymes, many important questions still remain unanswered regarding the identity of the molecules and mechanisms involved in $\mathrm{O}_{2}$ sensing. Identification of the $\mathrm{O}_{2}$-sensing molecules provides insights into how organisms detect changes in $\mathrm{O}_{2}$ level. Indeed, TRPA1 activation during hypoxia is mediated by Pro hydroxylation, as is the modulation of the well-known $\mathrm{O}_{2}$-sensitive transcription factor, HIF. To further our understanding of $\mathrm{O}_{2}$-sensing TRP channels, identification of redox-sensitive factors that interact with TRP channels (as seen with $\mathrm{K}_{\mathrm{Ca}}$ channels and RyR1) will be important. In addition, $\mathrm{O}_{2}$-dependent translocation between intracellular compartments and the plasma membrane, as seen for the GLUT1 transporter, may also be at play in TRP-dependent $\mathrm{O}_{2}$ sensing mechanisms.

Studies of $\mathrm{O}_{2}$-sensitive TRP channels have now matured from the functional characterization of single molecules to the analysis and integration of complex molecular systems controlled by TRPs. Ultimately, the delineation of these TRP-dependent $\mathrm{O}_{2}$ sensory networks could lead to the development of novel pharmacological tools for use in a broad spectrum of pathophysiological conditions that have $\mathrm{O}_{2}$ imbalance as part of their etiology. 


\section{Figure legends}

Fig. 1. Oxygen-sensitive TRP channels. TRPA1, TRPM2, TRPM7, TRPC1, TRPC3, TRPC6, TRPV1 and TRPV4 indirectly sense $\mathrm{O}_{2}$ under hypoxia (indicated in green). TRPA1 directly sense $\mathrm{O}_{2}$ under hyperoxia (indicated in red).

Fig. 2. Bidirectional regulation of TRPA1 channel activity by $\mathrm{O}_{2}$. Single-channel traces in cell-attached mode illustrate step-wise opening and closing, which keeps the membrane potential at approximately $-60 \mathrm{mV}$. Proline hydroxylases (PHDs) hydroxylate specific Pro residues in the $N$-terminal AR domain of TRPA1 protein in hyperoxia and normoxia, whereas a decrease in $\mathrm{O}_{2}$ concentration reduces PHD activity and relieves TRPA1 from this hydroxylation, leading to channel activation. In hyperoxia, $\mathrm{O}_{2}$ oxidizes specific Cys residues, thereby activating TRPA1. The sulfhydryl group(s) of these key Cys residues may be modified to sulfenic acid in the non-oxidized state of TRPA1, but may form a disulfide bond(s) when the channel is oxidized. These oxidation mechanisms over-ride the inhibition by Pro hydroxylation to activate TRPA1. These activation mechanisms are advantageous because they add versatility to the biophysical mechanisms that the cells use to adapt or respond to environmental changes.

Fig. 3. Oxidation sensitivity of TRP channels. Range of redox potentials for activation of respective TRP channels. The redox potential of $\mathrm{O}_{2}(-2,765 \mathrm{mV})$ is less negative than the threshold redox potential for TRPA1. 
Oxygen

Hypoxia Hyperoxia

\begin{tabular}{l} 
indirect \\
-TRPA1 \\
.TRPM2 \\
TRPM7 \\
TRRPC1 \\
.TRPC3 \\
.TRPC6 \\
TRRP1 \\
-TRPV4 \\
\hline
\end{tabular}

direct

- TRPA1

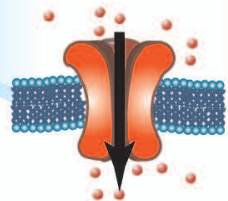

Mori et al.

Figure 1 


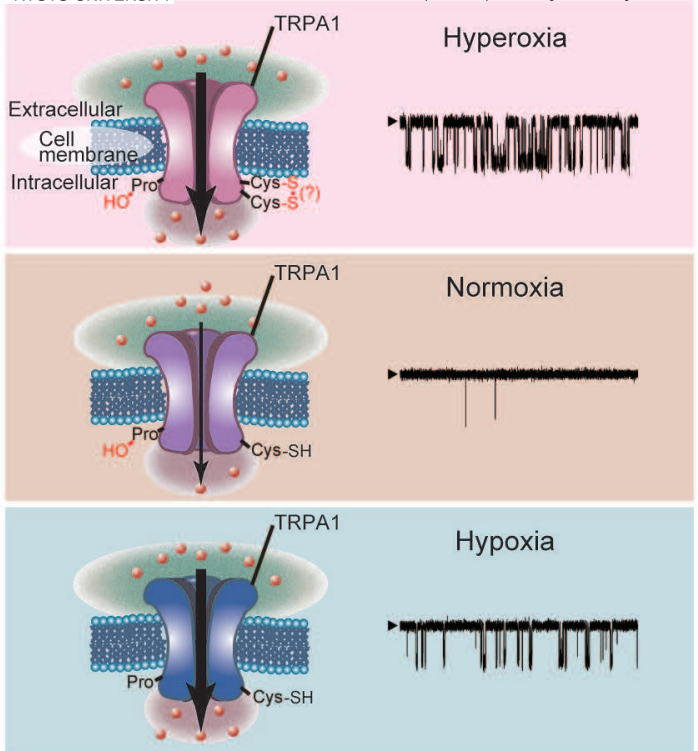

\section{Mori et al. Figure 2}




\section{Oxygen}

TRPA1

TRPV4

\section{TRPC5}

TRPV3

TRPV2

Redox potential (mV) 


\section{References}

1. Aarts M, Iihara K, Wei WL, Xiong ZG, Arundine M, Cerwinski W, MacDonald JF, Tymianski M (2003) A key role for TRPM7 channels in anoxic neuronal death. Cell 115: $863-877$

2. Acker T, Acker H (2004) Cellular oxygen sensing need in CNS function: physiological and pathological implications. J Exp Biol 207:3171-3188

3. Amador FJ, Liu S, Ishiyama N, Plevin MJ, Wilson A, MacLennan DH, Ikura M (2009) Crystal structure of type I ryanodine receptor amino-terminal beta-trefoil domain reveals a disease-associated mutation "hot spot” loop. Proc Natl Acad Sci U S A 106:11040-11044

4. Aracena-Parks P, Goonasekera SA, Gilman CP, Dirksen RT, Hidalgo C, Hamilton SL (2006) Identification of cysteines involved in S-nitrosylation, S-glutathionylation, and oxidation to disulfides in ryanodine receptor type 1 . J Biol Chem 281:40354-40368

5. Arpan G (2004) Head injury research: what have we learnt? Indian J Crit Care Med 8:111-115

6. Babior BM (2004) NADPH oxidase. Curr Opin Immunol 16:42-47 
7. Bautista DM, Movahed P, Hinman A, Axelsson HE, Sterner O, Högestätt ED, Julius D, Jordt SE, Zygmunt PM (2005) Pungent products from garlic activate the sensory ion channel TRPA1. Proc Natl Acad Sci U S A 102:12248-12252

8. Behrooz A, Ismail-Beigi F (1999) Stimulation of glucose transport by hypoxia: signals and mechanisms. Physiology 14:105-110

9. Berenbrink M, Völkel S, Heisler N, Nikinmaa M (2000) O2-dependent K+ fluxes in trout red blood cells: the nature of $\mathrm{O} 2$ sensing revealed by the $\mathrm{O} 2$ affinity, cooperativity and pH dependence of transport. J Physiol 526:69-80

10. Bessac BF, Jordt SE (2008) Breathtaking TRP channels: TRPA1 and TRPV1 in airway chemosensation and reflex control. Physiology (Bethesda) 23:360-370

11. Bessac BF, Sivula M, von Hehn CA, Escalera J, Cohn L, Jordt SE (2008) TRPA1 is a major oxidant sensor in murine airway sensory neurons. J Clin Invest 118:1899-1910

12. Birmingham K (2002) Future of neuroprotective drugs in doubt. Nat Med 8:5

13. Buckler KJ (1997) A novel oxygen-sensitive potassium current in rat carotid body type I cells. J Physiol 498:649-662. 
14. Butenko O, Dzamba D, Benesova J, Honsa P, Benfenati V, Rusnakova V, Ferroni S, Anderova M (2012) The increased activity of TRPV4 channel in the astrocytes of the adult rat hippocampus after cerebral hypoxia/ischemia. PLoS ONE 7:e39959

15. Carter AJ (1998) The importance of voltage-dependent sodium channels in cerebral ischaemia. Amino Acids 14:159-169

16. Conforti L, Millhorn DE (1997) Selective inhibition of a slow-inactivating voltage-dependent K+ channel in rat PC12 cells by hypoxia. J Physiol 502:293-305

17. Cummins TR, Jiang C, Haddad GG (1993) Human neocortical excitability is decreased during anoxia via sodium channel modulation. J Clin Invest 91:608-615

18. Cvetkov TL, Huynh KW, Cohen MR, Moiseenkova-Bell VY (2011) Molecular architecture and subunit organization of TRPA1 ion channel revealed by electron microscopy. J Biol Chem 286:38168-38176

19. De Sanctis GT, Green FH, Remmers JE (1991) Ventilatory responses to hypoxia and hypercapnia in awake rats pretreated with capsaicin. J Appl Physiol 70:1168-1174

20. Delpiano MA, Hescheler J (1989) Evidence for a PO2-sensitive K+ channel in the type-I cell of the rabbit carotid body. FEBS Lett 249:195-198

21. Duncan LM, Deeds J, Hunter J, Shao J, Holmgren LM, Woolf EA, Tepper RI, 
Shyjan AW (1998) Down-regulation of the novel gene melastatin correlates with potential for melanoma metastasis. Cancer Res. 58:1515-1520

22. Enyedi P, Czirják G (2010) Molecular background of leak K+ currents: two-pore domain potassium channels. Physiol Rev 90:559-605

23. Eu JP, Sun J, Xu L, Stamler JS, Meissner G (2000) The skeletal muscle calcium release channel: coupled O2 sensor and NO signaling functions. Cell 102:499-509

24. Fearon IM, Palmer AC, Balmforth AJ, Ball SG, Mikala G, Schwartz A, Peers C (1997). Hypoxia inhibits the recombinant alpha 1C subunit of the human cardiac L-type Ca2+ channel. J Physiol 500:551-556

25. Franco-Obregón A, López-Barneo J (1996) Differential oxygen sensitivity of calcium channels in rabbit smooth muscle cells of conduit and resistance pulmonary arteries. J Physiol 491: 511-518

26. Franco-Obregon A, Lopez-Barneo J (1996) Low PO2 inhibits calcium channel activity in arterial smooth muscle cells. Am J Physiol Heart Circ Physiol 271:H2290-H2299

27. Ganfornina MD, López-Barneo J (1991) Single K+ channels in membrane patches of arterial chemoreceptor cells are modulated by $\mathrm{O} 2$ tension. Proc Natl Acad Sci U S A 88:2927-2930 
28. Gaudet R. (2008) A primer on ankyrin repeat function in TRP channels and beyond. Mol BioSyst 4:372-379

29. Gees M, Colsoul B, Nilius B (2010) The role of transient receptor potential cation channels in Ca2+ signaling. Cold Spring Harb Perspect Biol 2:a003962

30. Giaccia AJ, Simon MC, Johnson R (2004) The biology of hypoxia: the role of oxygen sensing in development, normal function, and disease. Genes Dev 18:2183-2194

31. Gibson JS, Cossins AR, Ellory JC (2000) Oxygen-sensitive membrane transporters in vertebrate red cells. J Exp Biol 203:1395-1407

32. Gonzalez C, Almaraz L, Obeso A, Rigual R (1994) Carotid body chemoreceptors: from natural stimuli to sensory discharges. Physiol Rev 74:829-898

33. Gray JM, Karow DS, Lu H, Chang AJ, Chang JS, Ellis RE, Marletta MA, Bargmann CI (2004) Oxygen sensation and social feeding mediated by a C. elegans guanylate cyclase homologue. Nature 430:317-322

34. Gruss M, Ettorre G, Stehr AJ, Henrich M, Hempelmann G, Scholz A (2006) Moderate hypoxia influences excitability and blocks dendrotoxin sensitive $\mathrm{K}^{+}$ currents in rat primary sensory neurones. Mol Pain 2:12 
35. Haase VH (2012) Renal cancer: Oxygen meets metabolism. Exp. Cell Res. 318:1057-1067

36. Hamilton SL, Serysheva II (2009) Ryanodine receptor structure: progress and challenges. J Biol Chem 284:4047-4051

37. Hammarström AKM, Gage PW (1998) Inhibition of oxidative metabolism increases persistent sodium current in rat CA1 hippocampal neurons. J Physiol 510:735-741

38. Hampl V, Bíbová J, Straňák Z, Wu X, Michelakis ED, Hashimoto K, Archer SL (2002) Hypoxic fetoplacental vasoconstriction in humans is mediated by potassium channel inhibition. Am J Physiol Heart Circ Physiol 283:H2440-H2449

39. Hara Y, Wakamori M, Ishii M, Maeno E, Nishida M, Yoshida T, Yamada H, Shimizu S, Mori E, Kudoh J, Shimizu N, Kurose H, Okada Y, Imoto K, Mori Y (2002) LTRPC2 Ca2+-permeable channel activated by changes in redox status confers susceptibility to cell death. Molecular Cell 9:163-173

40. Hawkins BJ, Irrinki KM, Mallilankaraman K, Lien YC, Wang Y, Bhanumathy CD, Subbiah R, Ritchie MF, Soboloff J, Baba Y, Kurosaki T, Joseph SK, Gill DL, Madesh M (2010) S-glutathionylation activates STIM1 and alters mitochondrial homeostasis. J Cell Biol 190:391-405 
41. Hetz SK, Bradley TJ (2005) Insects breathe discontinuously to avoid oxygen toxicity. Nature 433:516-519

42. Howe A, Pack RJ, Wise JC (1981) Arterial chemoreceptor-like activity in the abdominal vagus of the rat. J Physiol 320:309-318

43. Ikonomidou C, Turski L (2002) Why did NMDA receptor antagonists fail clinical trials for stroke and traumatic brain injury? Lancet Neurol 1:383-386

44. Ismail S, Sturrock A, Wu P, Cahill B, Norman K, Huecksteadt T, Sanders K, Kennedy T, Hoidal J (2009) NOX4 mediates hypoxia-induced proliferation of human pulmonary artery smooth muscle cells: the role of autocrine production of transforming growth factor- $\beta 1$ and insulin-like growth factor binding protein-3. Am J Physiol Lung Cell Mol Physiol 296:L489-L499

45. Ito S, Ohta $\mathrm{T}$, Nakazato $\mathrm{Y}$ (1999) Characteristics of 5-HT-containing chemoreceptor cells of the chicken aortic body. J Physiol 515:49-59

46. Jia J, Verma S, Nakayama S, Quillinan N, Grafe MR, Hurn PD, Herson PS (2011) Sex differences in neuroprotection provided by inhibition of TRPM2 channels following experimental stroke. J Cereb Blood Flow Metab 31:2160-2168

47. Jordt SE, Bautista DM, Chuang H, McKemy DD, Zygmunt PM, Höqestätt ED, Meng ID, Julius D (2004) Mustard oils and cannabinoids excite sensory nerve 
fibres through the TRP channel ANKTM1. Nature 427:260-265

48. Kaloyianni M, Rasidaki A (1996) Adrenergic responses of R. ridibunda red cells. J Exp Zool 276:175-185

49. Kaneko S, Kawakami S, Hara Y, Wakamori M, Itoh E, Minami T, Takada Y, Kume T, Katsuki H, Mori Y, Akaike A (2006) A critical role of TRPM2 in neuronal cell death by hydrogen peroxide. J Pharmacol Sci 101:66-76

50. Kubin L, Alheid GF, Zuperku EJ, McCrimmon DR (2006) Central pathways of pulmonary and lower airway vagal afferents. J Appl Physiol 101:618-627

51. Lahiri S (2000) Historical perspectives of cellular oxygen sensing and responses to hypoxia. J Appl Physiol 88:1467-1473

52. Lahiri S, Roy A, Baby SM, Hoshi T, Semenza GL, Prabhakar NR (2006) Oxygen sensing in the body. Progress in Biophysics and Molecular Biology 91:249-286

53. Lange CAK, Bainbridge JWB (2012) Oxygen sensing in retinal health and disease. Ophthalmologica 227:115-131

54. Lanner JT, Georgiou DK, Joshi AD, Hamilton SL (2010) Ryanodine receptors: structure, expression, molecular details, and function in calcium release. Cold Spring Harb Perspect Biol 2:a003996 
55. Latorre R, Brauchi S, Orta G, Zaelzer C, Vargas G (2007) Thermo TRP channels as modular proteins with allosteric gating. Cell Calcium 42:427-438

56. Lee YM, Kim BJ, Chun YS, So I, Choi H, Kim MS, Park JW (2006) NOX4 as an oxygen sensor to regulate TASK-1 activity. Cell Signal 18:499-507

57. Liu Z, Wang R, Zhang J, Chen SRW, Wagenknecht T (2005) Localization of a disease-associated mutation site in the three-dimensional structure of the cardiac muscle ryanodine receptor. J Biol Chem 280:37941-37947

58. Lobo PA, Van Petegem F (2009) Crystal structures of the N-terminal domains of cardiac and skeletal muscle ryanodine receptors: insights into disease mutations. Structure 17:1505-1514

59. Longhurst JC, Tjen-A-Looi SC, Fu LW (2001) Cardiac sympathetic afferent activation provoked by myocardial ischemia and reperfusion. Mechanisms and reflexes. Ann N Y Acad Sci 940: 74-95

60. López-Barneo J, Pardal R, Ortega-Sáenz P (2001) Cellular mechanism of oxygen sensing. Annu Rev Physiol 63: 259-287

61. Lu W, Wang J, Shimoda LA, Sylvester JT (2008) Differences in STIM1 and TRPC expression in proximal and distal pulmonary arterial smooth muscle are associated with differences in Ca2+ responses to hypoxia. Am J Physiol Lung Cell Mol 
Physiol 295:L104-L113

62. Macpherson LJ, Geierstanger BH, Viswanath V, Bandell M, Eid SR, Hwang S, Patapoutian A (2005) The pungency of garlic: activation of TRPA1 and TRPV1 in response to allicin. Curr Biol 15:929-934

63. McKemy DD, Neuhausser WM, Julius D (2002) Identification of a cold receptor reveals a general role for TRP channels in thermosensation. Nature 416:52-58

64. McNulty S, Fonfria E (2005) The role of TRPM channels in cell death. Pflugers Arch 451:235-242

65. Meller ST, Gebhart GF (1992) A critical review of the afferent pathways and the potential chemical mediators involved in cardiac pain. Neuroscience 48:501-524

66. Motais R, Garcia-Romeu F, Borgese F (1987) The control of $\mathrm{Na}+\mathrm{H}+$ exchange by molecular oxygen in trout erythrocytes. A possible role of hemoglobin as a transducer. J Gen Physiol 90:197-207

67. Morris GF, Bullock R, Marshall SB, Marmarou A, Maas A, Marshall LF (1999) Failure of the competitive N-methyl-D-aspartate antagonist selfotel (CGS 19755) in the treatment of severe head injury: results of two phase III clinical trials. The selfotel investigators. J Neurosurg 91:737-743 
68. Murphy PJ (2005) The fetal circulation. Contin Educ Anaesth Crit Care Pain $5: 107-112$

69. Muzyamba MC, Cossins AR, Gibson JS (1999) Regulation of $\mathrm{Na}+-\mathrm{K}+-2 \mathrm{Cl}-$ cotransport in turkey red cells: the role of oxygen tension and protein phosphorylation. J Physiol 517:421-429

70. Nadler MJS, Hermosura MC, Inabe K, Perraud AL, Zhu Q, Stokes AJ, Kurosaki T, Kinet JP, Penner R, Scharenberg AM, Fleig A (2001) LTRPC7 is a Mg2+ ATP-regulated divalent cation channel required for cell viability. Nature 411:590-595

71. Naeije R, Brimioulle S (2001) Physiology in medicine: importance of hypoxic pulmonary vasoconstriction in maintaining arterial oxygenation during acute respiratory failure. Crit Care 5:67-71

72. Nassenstein C, Kwong K, Taylor-Clark T, Kollarik M, Macglashan DM, Braun A, Undem BJ (2008) Expression and function of the ion channel TRPA1 in vagal afferent nerves innervating mouse lungs. J Physiol 586:1595-1604

73. Neubauer JA, Sunderram J (2004) Oxygen-sensing neurons in the central nervous system. J Appl Physiol 96:367-374

74. Ng LC, O’Neill KG, French D, Airey JA, Singer CA, Tian H, Shen XM, Hume JR 
(2012) TRPC1 and Orai1 interact with STIM1 and mediate capacitative Ca2+ entry caused by acute hypoxia in mouse pulmonary arterial smooth muscle cells. Am J Physiol Cell Physiol 303:C1156-C1172

75. Nilius B, Appendino G, Owsianik G (2012) The transient receptor potential channel TRPA1: from gene to pathophysiology. Pflugers Arch Eur J Physiol 464:425-458

76. Nilius B, Owsianik G, Voets T, Peters JA (2007) Transient receptor potential cation channels in disease. Physiol Rev 87:165-217

77. Nishida M, Hara Y, Yoshida T, Inoue R, Mori Y (2006) TRP Channels: molecular diversity and physiological function. Microcirculation 13:535-550

78. Numata T, Kiyonaka S, Kato K, Takahashi N, Mori Y (2011) In: Zhu MX (ed) TRP Channels, Boca Raton (FL), CRC Press, Chapter 3

79. Olah ME, Jackson MF, Li H, Perez Y, Sun HS, Kiyonaka S, Mori Y, Tymianski M, MacDonald JF (2009) Ca2+-dependent induction of TRPM2 currents in hippocampal neurons. J Physiol 587:965-979

80. O’Kelly I, Stephens RH, Peers C, Kemp PJ (1999) Potential identification of the O2-sensitive $\mathrm{K}+$ current in a human neuroepithelial body-derived cell line. Am J Physiol Lung Cell Mol Physiol 276:L96-L104 
81. Pan HL, Chen SR (2004) Sensing tissue ischemia another new function for capsaicin receptors? Circulation 110:1826-1831

82. Pani B, Bollimuntha S, Singh BB (2012) The TR (i)P to $\mathrm{Ca}^{2+}$ signaling just got STIMy: an update on STIM1 activated TRPC channels. Front Biosci 17:805-823

83. Peers C (1990) Hypoxic suppression of K+ currents in type I carotid body cells: selective effect on the Ca2(+)-activated K+ current. Neurosci Lett 119:253-256

84. Peier AM, Moqrich A, Hergarden AC, Reeve AJ, Andersson DA, Story GM, Earley TJ, Dragoni I, McIntyre P, Bevan S, Patapoutian A (2002) A TRP channel that senses cold stimuli and menthol. Cell 108:705-715

85. Pendyala S, Gorshkova IA, Usatyuk PV, He D, Pennathur A, Lambeth JD, Thannickal VJ, Natarajan V (2009) Role of Nox4 and Nox2 in hyperoxia-induced reactive oxygen species generation and migration of human lung endothelial cells. Antioxid Redox Signal 11:747-764

86. Perraud AL, Fleig A, Dunn CA, Bagley LA, Launay P, Schmitz C, Stokes AJ, Zhu Q, Bessman MJ, Penner R, Kinet JP, Scharenberg AM (2001) ADP-ribose gating of the calcium-permeable LTRPC2 channel revealed by Nudix motif homology. Nature 411:595-599

87. Petrotchenko EV, Yamaguchi N, Pasek DA, Borchers CH, Meissner G (2011) Mass spectrometric analysis and mutagenesis predict involvement of multiple cysteines 
in redox regulation of the skeletal muscle ryanodine receptor ion channel complex. Res Rep Biol 2011:13-21

88. Post JM, Hume JR, Archer SL, Weir EK (1992) Direct role for potassium channel inhibition in hypoxic pulmonary vasoconstriction. Am J Physiol Cell Physiol 262:C882-C890

89. Quaegebeur A, Carmeliet P (2010) Oxygen sensing: a common crossroad in cancer and neurodegeneration. Curr. Top. Microbiol Immunol 345:71-103

90. Rezvani HR, Ali N, Nissen LJ, Harfouche G, Verneuil H, de Taïeb A, Mazurier F (2011) HIF-1 $\alpha$ in epidermis: oxygen sensing, cutaneous angiogenesis, cancer, and non-cancer disorders. J Invest Dermatol 131:1793-1805

91. Runnels LW, Yue L, Clapham DE (2001) TRP-PLIK, a bifunctional protein with kinase and ion channel activities. Science 291:1043-1047

92. Schofield CJ, Ratcliffe PJ (2004) Oxygen sensing by HIF hydroxylases. Nat. Rev. Mol. Cell Biol. 5:343-354

93. Semenza GL, Wang GL (1992) A nuclear factor induced by hypoxia via de novo protein synthesis binds to the human erythropoietin gene enhancer at a site required for transcriptional activation. Mol Cell Biol 12:5447-5454 
94. Semenza GL (1999) Regulation of mammalian O2 homeostasis by hypoxia-inducible factor 1. Annu Rev Cell Dev Biol 15:551-578

95. Shan D, Marchase RB, Chatham JC (2008) Overexpression of TRPC3 increases apoptosis but not necrosis in response to ischemia-reperfusion in adult mouse cardiomyocytes. Am J Physiol Cell Physiol 294:C833-C841

96. Stea A, Nurse CA (1991) Whole-cell and perforated-patch recordings from O2-sensitive rat carotid body cells grown in short- and long-term culture. Pflugers Arch 418:93-101

97. Story GM, Peier AM, Reeve AJ, Eid SR, Mosbacher J, Hricik TR, Earley TJ, Hergarden AC, Andersson DA, Hwang SW, McIntyre P, Jegla T, Bevan S, Patapoutian A (2003) ANKTM1, a TRP-like channel expressed in nociceptive neurons, is activated by cold temperatures. Cell 112:819-829

98. Sun HS, Jackson MF, Martin LJ, Jansen K, Teves L, Cui H, Kiyonaka S, Mori Y, Jones M, Forder JP, Golde TE, Orser BA, Macdonald JF, Tymianski M (2009) Suppression of hippocampal TRPM7 protein prevents delayed neuronal death in brain ischemia. Nat Neurosci 12:1300-1307

99. Sun J, Xin C, Eu JP, Stamler JS., Meissner G (2001) Cysteine-3635 is responsible for skeletal muscle ryanodine receptor modulation by NO. Proc Natl Acad Sci U S A 98:11158-11162 
100. Sun MK, Reis DJ (1994) Hypoxia-activated Ca2+ currents in pacemaker neurones of rat rostral ventrolateral medulla in vitro. J Physiol 476:101-116

101. Sun QA, Hess DT, Nogueira L, Yong S, Bowles DE, Eu J, Laurita KR, Meissner G, Stamler JS (2011) Oxygen-coupled redox regulation of the skeletal muscle ryanodine receptor-Ca2+ release channel by NADPH oxidase 4. Proc Natl Acad Sci U S A 108:16098-16103

102. Takahashi N, Kuwaki T, Kiyonaka S, Numata T, Kozai D, Mizuno Y, Yamamoto S, Naito S, Knevels E, Carmeliet P, Oga T, Kaneko S, Suga S, Nokami T, Yoshida J, Mori Y (2011) TRPA1 underlies a sensing mechanism for $\mathrm{O}_{2}$. Nat Chem Biol 7:701-711

103. Thompson RJ, Jackson A, Nurse CA (1997) Developmental loss of hypoxic chemosensitivity in rat adrenomedullary chromaffin cells. J Physiol 498:503-510

104. Tymianski M (2011) Emerging mechanisms of disrupted cellular signaling in brain ischemia. Nat Neurosci 14:1369-1373

105. Vaca L (2010) SOCIC: the store-operated calcium influx complex. Cell Calcium 47:199-209 
106. Venkatachalam K, Montell C (2007) TRP Channels. Annu Rev Biochem 76:387-417

107. Voets T (2012) Quantifying and modeling the temperature-dependent gating of TRP channels. In: Nilius B, Amara SG, Gudermann T, Jahn R, Lill R, Offermanns S, Petersen $\mathrm{OH}$ (eds) Reviews of Physiology, Biochemistry and Pharmacology, Reviews of Physiology, Biochemistry and Pharmacology. Springer, Berlin Heidelberg, pp 91-119

108. Voets T, Droogmans G, Wissenbach U, Janssens A, Flockerzi V, Nilius B (2004) The principle of temperature-dependent gating in cold- and heat-sensitive TRP channels. Nature 430:748-754

109. Voets T, Talavera K, Owsianik G, Nilius B (2005) Sensing with TRP channels. Nat Chem Biol 1:85-92

110. Voss AA, Lango J, Ernst-Russell M, Morin D, Pessah IN (2004) Identification of hyperreactive cysteines within ryanodine receptor type 1 by mass spectrometry. $\mathrm{J}$ Biol Chem 279:34514-34520

111. Webb JD, Coleman ML, Pugh CW (2009) Hypoxia, hypoxia-inducible factors (HIF), HIF hydroxylases and oxygen sensing. Cell Mol Life Sci 66:3539-3554

112. Weir EK, López-Barneo J, Buckler KJ, Archer SL (2005) Acute oxygen-sensing mechanisms. N Engl J Med 353:2042-2055 
113. Weir EK, Olschewski A (2006) Role of ion channels in acute and chronic responses of the pulmonary vasculature to hypoxia. Cardiovasc Res 71:630-641

114. Weissmann N, Dietrich A, Fuchs B, Kalwa H, Ay M, Dumitrascu R, Olschewski A, Storch U, Mederos Y, Schnitzler M, Ghofrani HA, Schermuly RT, Pinkenburg O, Seeger W, Grimminger F, Gudermann T (2006) Classical transient receptor potential channel 6 (TRPC6) is essential for hypoxic pulmonary vasoconstriction and alveolar gas exchange. Proc Natl Acad Sci U S A 103:19093-19098

115. Wenger RH (2000) Mammalian oxygen sensing, signalling and gene regulation. J Exp Biol 203: 1253-1263

116. Xie YF, MacDonald JF, Jackson MF (2010) TRPM2, calcium and neurodegenerative diseases. Int J Physiol Pathophysiol Pharmacol 2:95-103

117. Yoshida T, Inoue R, Morii T, Takahashi N, Yamamoto S, Hara Y, Tominaga M, Shimizu S, Sato Y, Mori Y (2006) Nitric oxide activates TRP channels by cysteine S-nitrosylation. Nat Chem Biol 2:596-607

118. Youngson C, Nurse C, Yeger H, Cutz E (1993) Oxygen sensing in airway chemoreceptors. Nature 365:153-155 
119. Zhu WH, Conforti L, Czyzyk-Krzeska MF, Millhorn DE (1996) Membrane depolarization in PC-12 cells during hypoxia is regulated by an O2-sensitive $\mathrm{K}+$ current. Am J Physiol Cell Physiol 271:C658-C665 